\title{
Use of dexmedetomidine with Propofol in modified electroconvulsive therapy: stable hemodynamics, optimum seizure duration and early recovery
}

\author{
Keerty Garg ${ }^{1}$, Kiran Sharma ${ }^{1}$, Mohit Jindal ${ }^{2 *}$ and Aseem Garg ${ }^{3}$ \\ ${ }^{1}$ Department of Anesthesia, Kalpana Chawla Govt Medical College, India \\ ${ }^{2}$ Department of Orthopedics, Kalpana Chawla Govt Medical College, India \\ ${ }^{3}$ Department of Medicine, VMMC and SJH, India
}

\begin{abstract}
Background: Modified electroconvulsive therapy (ECT) under anesthesia is an important modality in the treatment of severe, persistent depression; bipolar disorder and schizophrenia; especially in cases resistant to pharmacologic therapy.

Aim: To study the effects of dexmedetomidine in attenuation of stress response, motor seizure duration and recovery times following ECT.

Materials and methods: 60 cases aged between 18-50 years of ASA grade I and II; were randomly divided into two groups of 30 each. Group A received normal saline (control) while Group B received dexmedetomidine $1 \mu \mathrm{g} / \mathrm{kg}$ diluted to a volume of $20 \mathrm{ml}$ over 10 minutes; followed by induction with propofol $1 \mathrm{mg} / \mathrm{kg}$ and muscle relaxation with succinylcholine, $0.75 \mathrm{mg} / \mathrm{kg}$. Hemodynamic parameters at baseline, after study drug infusion, after induction and after ECT application were recorded at different time intervals. The motor seizure duration using arm isolation method, recovery times and time to home readiness were noted.

Results: The maximum increase in hemodynamic parameters was seen following the ECT current application. Post-ECT rise in mean arterial blood pressure (MAP) and heart rate $(\mathrm{HR})$ in dexmedetomidine group was significantly less $(\mathrm{p}<0.001)$ as compared to control group at 2, 4, 6 and 8 minutes using unpaired t- test. There was no significant difference in motor seizure activity duration. Emergence and recovery times were assessed using PADSS criteria which showed no prolongation in dexmedetomidine group.
\end{abstract}

Conclusion: Dexmedetomidine in a dose of $1 \mu \mathrm{g} / \mathrm{kg}$ attenuate the hyperdynamic response to ECT without affecting the seizure duration and has a more favorable response in view of smooth emergence and no adverse effects on recovery duration.

\section{Introduction}

Electroconvulsive therapy is a well- established treatment for severe depression in patients who have not responded to pharmacotherapy. Nowadays almost all the ECT procedures are performed under general anesthesia; also known as modified ECT. However, it is commonly associated with acute hyperdynamic responses, including initial parasympathetic response followed by transient hypertension and tachycardia due to release of catecholamines in the body. During the sympathetic response, systolic blood pressure may increase by $30-40 \%$ and heart rate may increase by $20 \%$ (or more) [1]. These responses may be harmful to patients with ischemic heart disease, hypertension and cerebrovascular disease. To attenuate this stress response, many pharmacological agents such as beta blockers, calcium channel blockers, alpha2-agonists, direct-acting vasodilators and local anesthetics were tried [2-6]. Dexmedetomidine is a centrally acting highly specific $\alpha-2$ adrenergic agonist with $\alpha 2$ : $\alpha 1$ binding selectivity ratio of 1620:1 compared to 220:1 for clonidine. The advantages of intravenous dexmedetomidine as premedicant in anesthesia include sedation, analgesia, anxiolysis and improved haemodynamic stability. It also effectively reduces the requirement of anesthetics [7]. Emergence agitation (excitement, restlessness and panic) may occur in some patients after ECT [8]. Dexmedetomidine is very effective in the management of emergence agitation following ECT.
For ECT, the optimal seizure duration remains unclear. As per psychiatry point of view, an adequate motor seizure is defined as one that lasts more than $25-30 \mathrm{sec}$. Too short $(<10 \mathrm{sec})$ or too long $(>120 \mathrm{sec})$ may reduce clinical efficacy [1]. The objectives of anesthesia to be kept in mind for modified ECT include rapid loss of consciousness, attenuation of hemodynamic responses, avoidance of gross movements, minimal interference with seizure induced by psychiatrist; prompt, smooth and early recovery of spontaneous ventilation and consciousness. Also early ambulation and discharge to home should be considered.

Therefore, the present study was designed to study the effects of dexmedetomidine as premedicant; followed by induction with propofol and muscle relaxation by succinylcholine in attenuating the hemodynamic stress responses, motor seizure activity duration and recovery times in patients who underwent ECT.

${ }^{\star}$ Correspondence to: Mohit Jindal, Department of Orthopedics, Kalpana Chawla Govt. Medical College, India, E-mail: mohitjindal2006@gmail.com

Key words: modified electroconvulsive therapy, dexmedetomidine, propofol, seizure, recovery

Received: April 04, 2018; Accepted: April 21, 2018; Published: April 25, 2018 


\section{Materials and methods}

After institutional ethical committee approval, 60 cases were taken in this prospective randomized double blind controlled study. The patients were informed about the procedure and the study. Informed consent was obtained from the patients and caretakers in the prescribed form. Patients belonging to ASA class I and II, aged 18-50 years having major depressive disorder (suicidal patients), schizophrenia, catatonia (in which first line treatment failed) or bipolar disorder were included. Patients with AV conduction block greater than 1st degree, history of major illness like tuberculosis, bronchial asthma, hypertension, recent stroke, acute respiratory disorder, an intracranial mass, raised intracranial pressure (ICP) from any cause, heart rate (HR) less than $50 \mathrm{bpm}$, systolic blood pressure (SBP) $<90 \mathrm{mmHg}$ or history of drug allergy to interventional drugs and pregnant females were excluded.

The study population was randomly divided into 2 groups (group A and B) with 30 cases in each group using sealed envelopes containing the name of the group, and patient was asked to pick up the envelope. The envelope was opened by senior anesthesiologist who was assigned to prepare the solutions and not involved with the study. Group A received normal saline (placebo) and Group B received dexmedetomidine $1 \mu \mathrm{g} / \mathrm{kg}$; total volume $20 \mathrm{ml}$ over 10 minutes in both the groups prior to induction using syringe pumps. Pre- anaesthetic evaluation was done thoroughly. Airway assessment using Mallampatti grading; eye examination to rule out papilloedema and other required investigations were done in all patients which included hemoglobin, electrocardiogram, X-ray chest, blood sugar, blood urea, serum creatinine. Chronic antidepressant medications were continued. Patient was kept nil by mouth for 6 hours. On arrival of the patient in the ECT/operating room, a 20 gauge cannula was inserted and an infusion of ringer lactate was started. Multiparameter monitors attached to record HR, non-invasive measurements of SBP, DBP, MAP, end tidal $\mathrm{CO} 2$ and continuous ECG monitoring and oxygen saturation (SpO2). After stabilization period of 5 minutes, baseline vitals were taken. Preoxygenation was done for 3 minutes via face mask with Bain's circuit. Induction was done with propofol $1 \mathrm{mg} / \mathrm{kg}$ and $0.75 \mathrm{mg} /$ $\mathrm{kg}$ succinylcholine. An oral soft bite block was placed and ECT shock current was applied. Psychiatrist was allowed to place bitemporal electrodes over forehead and a brief pulse stimulus of 90-120 volts MECT current for $2 \mathrm{~m} \mathrm{sec}$ was given to produce seizures. Effectiveness of ECT current was verified by appearance of tonic - clonic seizures. The controlled or assisted ventilation was continued with 100\% oxygen until patient resumed adequate spontaneous breathing. The HR, SBP, DBP and MAP were recorded at 0, 2, 4, 6, 8, 10 minutes and there after every 5 minutes till 30 minutes and then every 15 minutes; following the ECT current. The duration from ECT stimulus to cessation of clonic tonic motor activity in isolated arm was recorded using clinical method. The time from the end of succinylcholine administration until spontaneous breathing, eye opening, and obeying commands were recorded.

Patients were assessed for side effects like nausea, vomiting, hypotension/hypertension, respiratory depression after the electrical stimulus and were discharged from the post anesthetic care unit (PACU) to the psychiatry department according to PADSS criteria.

\section{Analysis}

Data analysis was carried out using the SPSS package (Version 21). Quantitative variables were presented as mean \pm SD and the differences were assessed using an independent sample $t$-test. Qualitative variables were presented as numbers and percentages and Chi-square test was used for comparison. The alternative hypothesis was assumed and value of $P \leq 0.05$ was considered to be statistically significant.

\section{Results}

In this study, 60 cases were taken which were divided into 2 groups of 30 each.

Group A ( $\mathrm{n}=30)$ Placebo (normal saline followed by induction with propofol)

Group B $(\mathrm{n}=30)$ Dexmedetomidine followed by induction with propofol.

The following observations were recorded and the results were statistically analysed.

\section{Demographic data}

The mean age, weight and gender were comparable among both the groups in the study as shown in the Table 1.

\section{Comparison of baseline variables}

The baseline variables like Heart Rate, Systolic Blood pressure, Diastolic Blood Pressure, Mean Arterial Pressure SpO2 were compared using unpaired $t$ test and were found statistically insignificant ( $\mathrm{p}$ value $>0.05$ ) in both the groups. Thus implying that both the groups were comparable in terms of their baseline parameters.

\section{Comparative statistical analysis of mean heart rate at different time intervals as per the study}

Results were analyzed using unpaired t-test at various time intervals. As shown in the Table 2, there was a significant rise in heart rate at the time of ECT current application ( $\mathrm{p}$ value $<0.01$ ) and it was much higher in control group about $29 \%$ (22 bpm) as compared to dexmedetomidine group, which showed very little increase in mean heart rate i.e. only $2 \%$ (2 bpm) from the baseline values. Also after dexmedetomidine infusion a significant reduction in heart rate was noted, which was about 6\% (5 $\mathrm{bpm})$. So the heart rate was stable and near to baseline at most of the times in group B (dexmedetomidine group).

These findings can be better appreciated from the line diagram drawn (Figure 1) showing a near constant and stable mean heart rate in the Dexmedetomidine group vis a vis comparing to the control group.

\section{Comparative statistical analysis of mean arterial pressure at different time intervals as per the study}

Similar to increase in heart rate, maximum rise in mean arterial pressure was seen at the time of ECT current application (Table 2) which was much higher in the control group i. e. about $35.24 \%(30 \mathrm{mmHg})$ as compared to dexmedetomidine group, which showed the increase in mean arterial pressure of only $6.11 \%(6 \mathrm{mmHg})$; when compared to baseline values.

Table 1: Demographic data

\begin{tabular}{|c|c|c|}
\hline- & Group A & Group B \\
\hline- & Mean \pm SD & Mean \pm SD \\
\hline Age & $33.4 \pm 9.05$ & $34 \pm 8.21$ \\
\hline Sex $(\mathrm{M} / \mathrm{F})$ & $20 / 10$ & $21 / 9$ \\
\hline Weight $(\mathrm{kg})$ & $56.12 \pm 6.14$ & $55.2 \pm 5.12$ \\
\hline
\end{tabular}


Table 2: showing comparative statistical analysis of Hemodynamic parameters at different time intervals as per the study

\begin{tabular}{|c|c|c|c|c|c|c|}
\hline Time Interval & $\begin{array}{l}\text { Mean Heart Rate } \\
\text { Group A (Control) }\end{array}$ & $\begin{array}{l}\text { Mean Heart Rate } \\
\text { Group B (Dexmede- } \\
\text { tomidine) }\end{array}$ & $\begin{array}{l}\text { Mean Heart Rate } \\
\text { Group A vs. B p value } \\
\text { with significance }\end{array}$ & $\begin{array}{c}\text { Mean Arterial Pressure } \\
\text { Group A (Control) }\end{array}$ & $\begin{array}{c}\text { Mean Arterial Pressure } \\
\text { Group B (Dexmedeto- } \\
\text { midine) }\end{array}$ & $\begin{array}{l}\text { Mean Arterial Pressure } \\
\text { Group A vs. B p value } \\
\text { with significance }\end{array}$ \\
\hline Baseline & $76.5 \pm 4.60$ & $77.03 \pm 3.84$ & 0.63 & $90.8 \pm 3.11$ & $91.6 \pm 2.48$ & 0.31 \\
\hline After study drug infusion & $77.03 \pm 3.90$ & $72.3 \pm 3.83$ & $<0.001$ & $91.0 \pm 2.97$ & $91.7 \pm 2.37$ & 0.09 \\
\hline After induction & $72.76 \pm 4.12$ & $71.76 \pm 3.33$ & 0.08 & $90.2 \pm 3.35$ & $89.3 \pm 2.35$ & 0.23 \\
\hline After ECT (0 min) & $98.5 \pm 4.97$ & $78.43 \pm 3.06$ & $<0.001$ & $122.8 \pm 3.63$ & $97.2 \pm 2.57$ & $<0.001$ \\
\hline $2 \mathrm{~min}$. & $94.8 \pm 5.08$ & $78.1 \pm 2.85$ & $<0.001$ & $115.6 \pm 2.86$ & $91.6 \pm 1.40$ & $<0.001$ \\
\hline $4 \mathrm{~min}$. & $90.2 \pm 4.46$ & $78.66 \pm 2.74$ & $<0.001$ & $109.5 \pm 2.47$ & $86.8 \pm 1.08$ & $<0.001$ \\
\hline $6 \mathrm{~min}$. & $85.86 \pm 3.41$ & $78.6 \pm 3.25$ & $<0.001$ & $100.8 \pm 1.89$ & $83.8 \pm 1.08$ & $<0.001$ \\
\hline $8 \mathrm{~min}$. & $81.6 \pm 3.47$ & $78.46 \pm 2.96$ & $<0.01$ & $96.0 \pm 1.24$ & $84.6 \pm 0.92$ & $<0.001$ \\
\hline $10 \mathrm{~min}$. & $76.9 \pm 2.49$ & $76.8 \pm 3.18$ & 0.89 & $92.8 \pm 1.79$ & $87.1 \pm 1.19$ & $<0.001$ \\
\hline $15 \mathrm{~min}$. & $76.56 \pm 4.06$ & $77.0 \pm 3.38$ & 0.29 & $90.6 \pm 2.49$ & $91.0 \pm 1.61$ & 0.42 \\
\hline $20 \mathrm{~min}$. & $76.66 \pm 3.70$ & $77.23 \pm 3.68$ & 0.55 & $91.3 \pm 2.89$ & $91.6 \pm 2.48$ & 0.73 \\
\hline $25 \mathrm{~min}$. & $77.03 \pm 4.01$ & $77.46 \pm 3.52$ & 0.66 & $91.0 \pm 2.97$ & $91.9 \pm 1.86$ & 0.06 \\
\hline $30 \mathrm{~min}$. & $77.06 \pm 3.92$ & $77.33 \pm 3.80$ & 0.79 & $91.1 \pm 2.58$ & $91.9 \pm 2.15$ & 0.19 \\
\hline $45 \mathrm{~min}$. & $77.03 \pm 4.01$ & $77.83 \pm 3.51$ & 0.41 & $91.0 \pm 2.69$ & $91.9 \pm 2.22$ & 0.14 \\
\hline $60 \mathrm{~min}$. & $76.5 \pm 4.60$ & $77.03 \pm 3.84$ & 0.63 & $91.0 \pm 3.00$ & $91.5 \pm 2.56$ & 0.49 \\
\hline
\end{tabular}

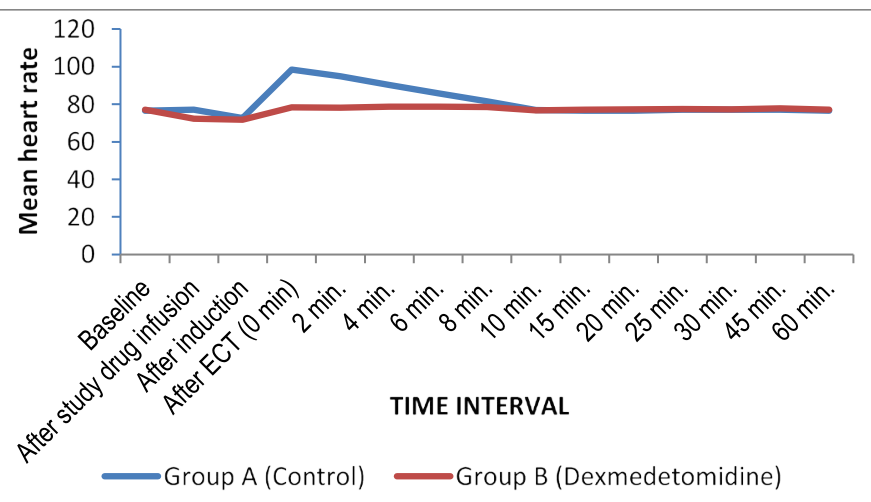

Figure 1: Line diagram showing changes in heart rate in both the groups at different time intervals as per the study

As stated above, parallel trends were seen in systolic and diastolic BP. When compared to baseline, rise in mean systolic blood pressure was higher in the control group i. e. about $36 \%$ (about $43 \mathrm{~mm} \mathrm{Hg}$ ) as compared to dexmedetomidine group, which showed the increase of only $4 \%$ (about $5 \mathrm{mmHg}$ ). Also rise in mean diastolic blood pressure was higher in control group i. e. about $34.42 \%(30 \mathrm{~mm} \mathrm{Hg})$ as compared to dexmedetomidine group, which showed the increase of $8 \%(6 \mathrm{~mm}$ $\mathrm{Hg}$ ) only; from the baseline values.

All the significant changes in hemodynamic variables ( $p$ value $<0.01$ ) were confined to 8-10 minutes following ECT current application; after which no significant variation was seen.

These findings can be better appreciated from the line diagram drawn (Figure 2) showing a near constant and stable Mean Arterial pressure in the Dexmedetomidine group vis a vis comparing to the control group.

\section{Comparison of seizure duration}

There was no significant difference in duration of motor seizure activity (group A- $27.26 \pm 3.68$ vs group B- $28.7 \pm 3.27$ ). (Table 3 )

\section{Comparison of recovery time in the study groups}

Recovery times were similar in both the groups (group A-508.26 \pm $11.4 \mathrm{sec}$ vs group B-508.63 $\pm 10.37 \mathrm{sec}$ ) (Table 3 ).

An additional propofol dose was required in only 2 ECT sessions in dexmedetomidine group but in about 14 ECT sessions in control group. Also in 5 ECT sessions; motor seizure duration was less than 25 seconds.

Patients were shifted to the ward or were ready to go home when they met discharge criteria according to Post Anesthesia Discharge Scoring System (PADSS).

\begin{tabular}{|c|l|c|}
\hline \multirow{4}{*}{ Vital signs } & Categories & Points \\
\hline \multirow{4}{*}{ Activity } & BP and HR within 20\% of pre-operative baseline value & 2 \\
\cline { 2 - 3 } & BP and HR 20\%-40\% of pre-operative baseline value & 1 \\
\cline { 2 - 3 } & BP and HR $>$ 40\% of pre-operative value & 0 \\
\hline \multirow{2}{*}{$\begin{array}{c}\text { Nausea and } \\
\text { vomiting }\end{array}$} & Steady gait, no dizziness or meets pre-operative level & 2 \\
\cline { 2 - 3 } & Requires assistance & 1 \\
\hline \multirow{3}{*}{ Pain } & Unable to ambulate & 0 \\
\hline & Moderate/treated with parenteral medication & 2 \\
\hline & Severe/continues despite treatment & 1 \\
\hline & Minimal or no pain & 0 \\
\hline \multirow{2}{*}{$\begin{array}{c}\text { Surgical } \\
\text { bleeding }\end{array}$} & Severe (not acceptable) & 2 \\
\hline & None or Minimal (not requiring intervention) & 0 \\
\hline & Moderate & 2 \\
\hline & Severe & 1 \\
\hline & $\begin{array}{l}\text { Total patients' scoring } \geq 7 \text { for two consecutive measurements } \\
\text { can be discharge home. }\end{array}$ & 0 \\
\hline & & \\
\hline
\end{tabular}

A minimum score of $7 / 8$ or achieving same preoperative status is must prior to transferring the patient to a phase 3 recovery areas or home. Earlier a minimum score of $9 / 10$ was there in the PADSS criteria but in the present study category of surgical bleeding has been omitted as there is no need of this category.

\section{Discussion}

ECT induces generalized tonic-clonic epileptic seizure. The patients coming for ECT has already been taking a variety of anti-psychotic medications which makes them prone to even more exaggerated cardiovascular responses. Plasma epinephrine increases to 15 times normal level, and plasma norepinephrine can also become three times higher than under normal resting conditions, with peak levels occurring within 60 seconds of electrical stimulation. Similar to techniques used for tracheal intubation [9], many pharmacologic methods have been used in an attempt to blunt the hemodynamic effects of ECT. 


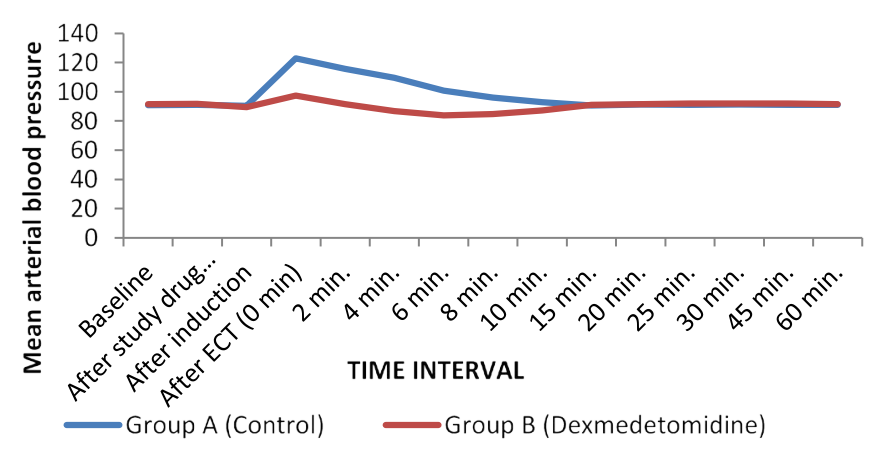

Figure 2: Line diagram showing variation in mean arterial blood pressure in both the groups at different intervals as per study

Table 3: Showing variation in seizure duration and Recovery Duration in the 2 groups

\begin{tabular}{|c|c|c|c|}
\hline Study Group & Group A (Control) & $\begin{array}{c}\text { Group B } \\
\text { (Dexmedetomidine) }\end{array}$ & P value \\
\hline Seizure Duration & $27.26 \pm 3.68$ & $28.7 \pm 3.27$ & 0.11 \\
\hline Recovery duration & $508.26 \pm 11.40$ & $508.63 \pm 10.37$ & 0.89 \\
\hline
\end{tabular}

Non significant $(\mathrm{p}>0.05)$

Various intravenous agents have been used for induction previously like thiopentone, midazolam, methohexital, etomidate and propofol. Propofol is associated with decreased incidence of nausea and vomiting [10], faster emergence, better early psychomotor and cognitive recovery $[11,12]$. Thus it can be considered an agent of choice for short day care procedure. Initial concerns that shorter seizures produced with propofol administration may compromise efficacy have not been empirically supported in the period immediately after ECT and have been offset by its demonstrated advantages [13,14]. Dexmedetomidine acts on adrenergic receptors in locus coeruleus in brain causing inhibition of adenylyl cyclase which results in stimulation of parasympathetic outflow and inhibition of sympathetic outflow overall causing reduction in CVS and CNS excitation. In our study post-ECT hyperdynamic responses were significantly less in the dexmedetomidine group at 0 , 2, 4, 6 and 8 min as compared with control group. This observation was similar to the findings of Begec et al. [15] who found that heart rate and MAP values were lower in a dexmedetomidine group at $0,1,3$ and 10 minutes. Shams and ElMasry [7] also found similar results; but in their study a combination of ketamine and propofol was used for induction. Optimum motor seizure duration has been used to assess the effectiveness of modified ECT. Fu and White [16] have reported that dexmedetomidine slightly extended the seizure activity duration during ECT. Contrary to their findings; our results were similar to those of Begec et al. [15], Mizrak et al. [17], Cohen Stewart [18] and Dodawad [19] who found no significant differences in the duration of seizures in their studies

Motor seizure duration, time to spontaneous breathing and obeying commands were comparable in both the groups.

Apart from stable hemodynamics; emergence was clear, without any confusion and smooth [20]. Premedication with low-dose dexmedetomidine reduces the total propofol requirement which in turn increases seizure duration, ensures rapid recovery without altering patient satisfaction $[21,22]$. As the recovery was not prolonged, our patients were ambulatory and could be discharged to home after around 30 minutes but we observed the patients for 60 minutes to check for any side effect of our interventional drugs as well as the procedure.
No patient experienced headache, respiratory depression, hypoxemia, bradycardia, hypotension, jaw pain and muscle spasms.

\section{Conclusion}

Since electroconvulsive therapy is a short procedure and can be completed in 8-10 minutes, the anesthetic agents used should have a rapid onset, short action, smooth recovery and no interference with seizure duration. In the present study, dexmedetomidine infusion as a premedicant did not prolong the recovery times. This drug may be superior to other drugs used for ECT because it is associated with stable cardiovascular and respiratory functions, decreased salivation and no interference with motor seizure duration of ECT. In brief, we concluded that dexmedetomidine has a more favorable response in view of stable hemodynamics, smooth emergence and recovery profile as well. However, the implications of these findings require further investigation.

The monitoring of seizure duration by observing tonic clonic activity and not using electroencephalogram (EEG) was a limitation of our study because EEG seizure duration activity may be longer than motor seizure activity.

\section{References}

1. Ding Z, White PF (2002) Anesthesia for electroconvulsive therapy. Anesth Analg 94 1351-1364. [Crossref]

2. Pal R, Pal VS (2015) Anesthesia for electroconvulsive therapy: A Noble approach. Int J Med Res Health Sci 4: 890-895.

3. Locala JA, Irefin SA, Malone D, Cywinski JB, Samuel SW, et al. (2005) The comparative hemodynamic effects of methohexital and remifentanil in electroconvulsive therapy. $J$ ECT 21: 12-5. [Crossref]

4. Kumar A, Mani R, Sharma DK (2012) A comparison of propofol and thiopentone for electroconvulsive therapy. J Anaesthesiol Clin Pharm 28: 353-357. [Crossref]

5. van den Broek WW, Groenland TH, Mulder PG, Kusuma A, Birkenhäger TK, et al (2008) Beta-blockers and electroconvulsive therapy: a review. Tijdschr Psychiatr 50: 205-215. [Crossref]

6. Boere E, Birkenhäger TK, Groenland TH, van den Broek WW (2014) Beta-blocking agents during electroconvulsive therapy: a review. Br J Anaesth 113: 43-51. [Crossref]

7. Shams T, El-Masry R (2014) Ketofol-dexmedetomidine combination in ECT: a punch for depression and agitation. Indian J Anaesth 58: 275-280. [Crossref]

8. Daniel WF (1995) ECT seizure duration and efficacy. Br J Psychiatry 166: 399-401. [Crossref]

9. Reddy SV, Balaji D, Ahmed SN (2014) Dexmedetomidine versus esmolol to attenuate the hemodynamic response to laryngoscopy and tracheal intubation: A randomized double-blind clinical study. Int J Appl Basic Med Res 4: 95-100. [Crossref]

10. Boey WK, Lai FO (1990) Comparison of propofol and thiopentone as anaesthetic agents for electroconvulsive therapy. Anaesthesia 45: 623-628. [Crossref]

11. Rouse EC (1988) Propofol for electroconvulsive therapy. Anaesthesia 43: 61-64.

12. Butterfield NN, Graf P, Macleod BA, Ries CR, Zis AP (2004) Propofol reduces cognitive impairment after electroconvulsive therapy. J ECT 20: 3-9. [Crossref]

13. Simpson KH, Halsall PJ, Carr CM, Stewart KG (1988) Propofol reduces seizure duration in patients having anaesthesia for electroconvulsive therapy. Br J Anaesth 61 : 343-344. [Crossref]

14. Avramov MN, Husain MM, White PF (1995) The comparative effects of methohexital, propofol, and etomidate for electroconvulsive therapy. Anesth Analg 81: 596-602. [Crossref]

15. Begec Z, Toprak HI, Demirbilek S, Erdil F, Onal D, et al. (2008) Dexmedetomidine blunts acute hyperdynamic responses to electroconvulsive therapy without altering seizure duration. Acta Anaesth Scand 52: 302-306. [Crossref]

16. Fu W, White PF (1999) Dexmedetomidine failed to block the acute hyperdynamic response to electroconvulsive therapy. Anesthesiology 90: 422-424. [Crossref] 
Garg K (2018) Use of dexmedetomidine with Propofol in modified electroconvulsive therapy: stable hemodynamics, optimum seizure duration and early recovery

17. Mizrak A1, Koruk S, Ganidagli S, Bulut M, Oner U (2009) Premedication with dexmedetomidine and midazolam attenuates agitation after electroconvulsive therapy. J Anesth 23: 6-10. [Crossref]

18. Cohen MB, Stewart JT (2013) Treatment of post-electroconvulsive therapy agitation with dexmedetomidine. JECT 29: 23-24. [Crossref]

19. Dodawad R, Sumalatha GB, Sandeep P, Jajee P (2015) Dexmedetomidine at a Dose of $0.6 \mathrm{microgram} / \mathrm{kg}$ in Attenuation of Hemodynamic Stress Response of Electroconvulsive Therapy. J Evidence based Medicine and Healthcare 2: 4771-4778.
20. Geretsegger C, Rochowanski E, Kartnig C, Unterrainer AF (1998) Propofol and methohexital as anesthetic agents for electroconvulsive therapy (ECT): A comparison of seizure-quality measures and vital signs. JECT 14: 28-35. [Crossref]

21. Tobias JD (2007) Dexmedetomidine: Applications in pediatric critical care and pediatric anesthesiology. Pediatr Crit Care Med 8: 115-131. [Crossref]

22. Grant SA, Breslin DS, MacLeod DB, Gleason D, Martin G (2004) Dexmedetomidine infusion for sedation during fiberoptic intubation: A report of three cases. J Clin Anesth 16: 124-126. [Crossref]

Copyright: (C2018 Garg K. This is an open-access article distributed under the terms of the Creative Commons Attribution License, which permits unrestricted use, distribution, and reproduction in any medium, provided the original author and source are credited. 